\title{
Study on Problems in Internal Control of Chinese Accounting Firms and Corresponding Countermeasures
}

\author{
Shuhui Qi \\ College of economics and management, Zhejiang Industry Polytechnic College, Shaoxing, Zhejiang, \\ 312000, China
}

Keywords: Accounting firm, Internal control, Financial management

\begin{abstract}
Enhancement of internal control of accounting firms can significantly improve management quality, risk prevention ability and market competitiveness of the firms and generate great influence on modernization construction and development of accounting firms. Thus, it is required to pay attention to it in practice. Based on analyzing internal control problem of Chinese accounting firms, this paper proposes the principles that internal control should follow and the countermeasures to solve problems, in the hope of offering certain support and reference for improving internal control ability of accounting firms and promoting better development of accounting firms in current society.
\end{abstract}

\section{Introduction}

Internal control theory has experienced several development stages overseas and has gained certain theoretical and practical results. However, influenced by economic development, internal control theory just starts in China and is moving towards internal control system from internal check system. It is gradually accepted by China's economic and financial field and generates certain positive influence on development of China's economy and society. This paper starts from internal control status of accounting firms, proposes several suggestions on improving internal control and expects to provide corresponding support for modernization construction and development of accounting firms.

\section{Problems existing in internal control of Chinese accounting firms}

Compared with rapid development and changes of international internal control theory, the study on internal control starts late in China and the development speed is also slow. It is still in initial transition stage to internal control system and starts to own the framework and rudiment of internal control. Thus, internal control level of accountants is relatively low. The major problems are as follows:

Management rules of accounting firms have defects and institutional arrangement is unsound. For accounting firms, rules play certain guiding and standardizing role for internal work. If rules go wrong, bad influence will inevitably appear to normal development of accounting firms. Thus, the formulation of relevant rules should comply with actual conditions of accounting firms and avoid the phenomenon of dealing with inspection by relevant departments and serious impacts on scientificity and rationality of the rules ${ }^{[1]}$. Meanwhile, since traditional laws on accountants include two types and they have certain conflicts in enterprise management. Thus, accounting firms have to formulate two rules. One is formulated according to regulations of financial development, and the other is drafted in line with regulations of industrial and commercial department. This directly results in low practicability of accounting firm rules and even makes the rules invalid. Corresponding bad influence is generated on construction and development of accounting firms.

Incentive mechanism lacks rationality and talent training mode is too rigid. In practical operation process, some accounting firms will implement commission distribution system according to the construction project. In other words, after a project is completed, certified public accountants or project assistants of an accounting firm will gain certain reward according to specific income proportion. Or some income is handed in the firm, and the personnel participating in execution will 
carry out uniform management and distribution ${ }^{[2]}$. Such distribution system is suitable for development of current economic society in China in the initial stage. However, with the era progress and social development, the defects of this distribution system gradually stand out. It overemphasizes materiality, which will result in excessive pursuit of short-term development to some extent. Besides, it overlooks the risks of accounting firms in management process and makes the firms caught in development crisis due to individual behaviors of accountants. Thus, adverse influence is caused to accounting firm construction. Accounting firms should enhance attention to scientific incentive mechanism construction, rationally adjust talent training mode and create corresponding conditions for internal control of accountants.

Cultural construction level of internal control is low. Some certified public accountants lack corresponding understanding of cultural construction of accounting firms, and they purely regard internal control as a manifestation form of coping with supervision and management department. This will not just increase management and operation cost of the firms, but also will result in low control efficiency and poor effect. This problem exists in management of Chinese accounting firms and may easily cause that managers deem internal control as a burden and let their decisions outmatch rules of internal control. Seriously bad impacts are thus generated on actual effect of internal control.

Execution strength of control activity is low. Incurrent stage, an overwhelming majority of accounting firms in China have established corresponding internal control rules in combination of their own development needs such as authorization, information processing, responsibility and performance evaluation. However, seeing from implementation situation of internal control, the anticipated effect of internal control system fails to be exerted. Relevant personnel pay excessive attention to time control, and ignore prevention and discovery of defects and shortcomings. Thus, accounting firms make up for defects only when problems happen. Internal control system becomes formalistic and loses the due function ${ }^{[3]}$.

\section{Principles accounting firms should stick to during enhancement of internal control management}

Goal-oriented principle. Adherence to goal-oriented principle can manifest initiative and dynamic nature of internal control work of accounting firms. Generally, any goal certainly has corresponding hierarchy. The process where accounting firms formulate relevant goals in combination of their development demand is also a process where they make active adjustment according to external market environment, while internal control is a means to continuously achieve goals of firms through corresponding management and control. Thus, internal control work is inevitably goal-oriented.

Principle of significance and systematicness combination. Simply speaking, systematicness means internal control work should be all-round, which is mainly reflected in process comprehensiveness in practical work ${ }^{[4]}$. Different from external framework used to manage work of accounting firms, internal control of accountants is imbedded in operation supervision and control process of accounting firms. Internal control mainly manages decision making, risks, personnel and distribution and can combine organically significance and systematicness.

Principle of combining explicit rights and responsibilities with fair reward and punishment. To stick to this principle in the work of accounting firms, accounting firms should regard work goal as the orientation, responsibility as the center and power as an important guarantee of improving work quality, improve employees' working enthusiasm through reward and punishment and give full play to actual effect of internal control.

Cost-benefit principle. From the perspective of social attribute, accounting firms belong to social attributes with special property and undertake corresponding social responsibility. However in essence, survival and development of accounting firms are closely related to profits. The profit is crucially influenced by cost benefit in realistic society. Thus, enhancement of internal control ability of accounting firms should stick to cost-benefit principle ${ }^{[2]}$. Meanwhile, sticking to implementing cost-benefit principle can embody differences of internal control system. Accountant vocation is an important link in social power and responsibility system and a significant constituent part of market 
supervision. In addition, it is an important supervisor of financial accounting production link and generates vital influence on sustainable and healthy development of socialist market economy.

\section{Measures to improve internal control status of Chinese accounting firms}

To enhance governmental macroeconomic regulation and control and fully mobilize leading role of government in various kinds of work. Local governments should lay down scientific macro-control policy in combination of actual conditions, give full play to leading role of relevant departments, create favorable working environment for enhancing internal control system and constructing internal control structure and promote further development of accounting firms. In the meantime, the government should focus on perfecting and improving economic competitive mechanism from the aspects of legislation and judicial system. Furthermore, the government should make sure all kinds of work are open and fair and construct efficient market rules. The legal department should make law enforcement strict, standardize and correct the order of market economy in combination of economic and social development demand, create favorable market competition environment, strengthen fairness and openness of economic competition, stimulate managers of accounting firms to enhance internal control awareness and boost internal control quality and level of accounting firms fundamentally.

To formulate and deeply implement various rules of accounting firms. Relevant rules of accounting firms are basic reference for firms to carry out management and external economic contact. As basic norms of accounting firms, the rules have very important influence on healthy operation and sustainable development of accounting firms. They are the foundation of accounting firm development in modern society, and also the soul of improving working quality and level, so they should be valued by accounting firms. Generally, the major organizational form of Chinese accounting firms is limited liability partnership. Scientific and reasonable accounting firm rules can enhance management and restriction of employees, facilitate development and improvement of internal control system of accounting firms and strengthen actual work effect.

To construct scientific examination and evaluation mechanism, and incentive and constraint system. For any enterprise and public institution, work incentive mechanism is the core content of internal management work system. As the key point of control work, work incentive mechanism is the precondition and important reference for maintaining normal operation of internal control of firms. Hence, accountants should show strong autonomous working consciousness and independent judgment ability in work, specify their working goals, fully excavate potential and strong points, acquire corresponding achievements in work, gradually achieve self-value and obtain social respect and approval etc. Therefore, accounting firms should fully respect personalized features of certified public accountants in human resource management, and take corresponding actions to stimulate them to work diligently and to make greater contributions to development of accounting firms.

To prevent risks overall through sound risk feedback mechanism. Internal control application has strong applicability and can penetrate in various aspects of relevant industries. With it, accounting firms can uniformly manage employees, properties and materials, construct risk prevention mechanism with complete content and advanced method and provide corresponding guidance for development accounting firms. With regard to its specific operation, all employees need to form harmonious working relations, create top-bottom professional working atmosphere, infusing risk awareness to every employee and support improving of work efficiency in order to establish all-round risk prevention awareness.

To pay attention to talent training and improve comprehensive quality of employees. The qualities of superior and comprehensive talents generally include politics, science, professional ethics, physical and psychological health, and specialty foundation. High-quality employees can deepen their understanding of internal control, further boost their ability to implement internal control system, intensify internal control quality and offer corresponding guarantee for future development. So, to improve internal control status, accounting firms should reinforce attention to talent training, take 
actions to boost employees' comprehensive quality and make contributions to modernization construction and development of firms.

To enhance internal control culture inspection and form positive working atmosphere in the firms. It can be seen from above analysis that, internal control culture is a significant constituent part of internal control system construction and exerts a crucial influence on improving internal control level. When employees are subtly influenced by internal control culture in practical work, the overall quality of accounting firm employees will certainly improve and finally the firm will gain the benefit. So, accounting firms should enhance attention to internal control culture construction, actively introduce advanced thought in work, carry out cultural, ideological and political education for employees, and offer entertainment time and space for employees so that they can generate sense of identity, and then conscientiously undertake responsibilities and complete tasks. As well, this will accelerate healthy and stable development of accounting firms in contemporary society.

\section{Conclusions}

In conclusion, internal control enhancement and management of accounting firms have very important effects on development of firms and further development of socialist market economy, so it should be highly valued by relevant employees. Thus, certain measures must be taken to enhance internal control construction and management in the new period, give full play to internal control effect and make corresponding contributions to modernization construction and development of accounting firms.

\section{Acknowledgments}

This paper is a part of the topic of 2014 university-level scientific research fund; the topic title is Study on Internal Control Problems of Accounting Firms, No.: 111001410920414002

\section{References}

[1] Lv Hongjing, Development Strategy of International Freight Forwarding Enterprises under E-commerce Environment. E-commerce, 2012(3):29-30.

[2] Che Wenli, Yao Changjia, Guan Jian et al., INTERNET-based Online Training of International Freight Forwarding Service. Journal of Changzhou Vocational College of Information Technology, 2013,12(2):41-44.

[3] Liu Xu, Study on Shipping E-commerce Platform Selection of Forwarding Enterprises. Daliann Maritime University, 2011.

[4] Xing Dacheng, Study on management policy of S International Freight Forwarding Company Based on E-commerce Platform . Tianjin University, 2013.

[5] Zhou Qixing, Study on Air Transportation Optimization of Small and Medium International Freight Forwarding Enterprises - Case Study of An International Freight Forwarding Company. Transportation Enterprise Management, 2013,28(5):45-47.

[6] Hu Xiaotang, Study on Transformation of Freight Forwarding Enterprises to Third-party Logistics Industry. E-commerce in China, 2014(1):263. 